\title{
Dosage Form for Suspension
}

National Cancer Institute

\section{Source}

National Cancer Institute. Dosage Form for Suspension. NCI Thesaurus. Code C60928.

A substance intended for administration as a suspension. 